\title{
TUTELA PROCESAL ORDINARIA Y PRIVILEGIADA (JURISDICCION CONSTITUCIONAL) DE LOS INTERESES DIFUSOS
}

\author{
POR \\ JOSE ALMAGRO NOSETE \\ Catedrático de Derecho Procesal. UNED
}

\begin{abstract}
SUMARIO
A) Proceso e intereses difusos: I. Preliminar. II. Dificultades de la noción «intereses difusos». III. Aproximación al concepto de «intereses difusos». IV. La tutela procesal de los «intereses difusos».-B) Perspectiva constitucional y protección procesal de los intereses difusos en España: V. Constitución española e «intereses difusos». VI. Sobre la tutela procesal, en general, de los «intereses difusos» en el sistema español.-C) Justicialidad constitucional de los intereses difusos: VII. Consideración general. VIII. Función del Defensor del Pueblo como tutor de «intereses difusos». IX. La acción de los ciudadanos ante el Tribunal Constitucional.-Nota bibliográfica.
\end{abstract}

\section{A) PROCESO E INTERESES DIFUSOS}

\section{PRELIMINAR}

La noción de «intereses difusos», más que a un concepto acabado y categotial, invoca una idea-fuerza renovadora de la clásica e insuficiente tutela procesal.

Tradicionalmente, la tutela procesal se presta al sujeto en su calidad de titular de un derecho o interés propio. Los derechos e intereses ajenos no pueden ser gestionados - las contadas excepciones confirman la regla- por quienes no alegan su titularidad, o sea, por los extraños a la relación jurídica o situación jurídica originadora del interés. En esta distinción radica la esencia del Derecho privado.

De aquí que esta diferencia, válida en cuanto contempla al sujeto jurídico como individuo, pierda utilidad cuando se considera al sujeto como miembro de una comunidad en la que, por necesidad que obliga a la solidaridad, comparte intereses que son sociales o colectivos, es decir, intereses que al tiempo son ajenos y propios, pero siempre comunes. Algunos de estos intereses sociales o colectivos, habitualmente de entre aquellos que tienen un carácter más 
general que sectorial o circunscrito a grupos específicos, son seleccionados por el Estado en forma de intereses públicos. Y el Estado se constituye en gestor y garante de estos intereses.

La tutela procesal de los intereses públicos se desarrolla básicamente por medio de las jurisdicciones penal y contencioso-administrativa. A tal fin se instituyen también órganos específicos (Ministerio Fiscal y Abogacía del Estado) legitimados para ejercitar activa o pasivamente el derecho a la jurisdicción en representación (el término no se emplea en sentido técnico procesal) de esos intereses. Cabe también que se legitime en régimen abierto (acción popular) al ciudadano para actuar en defensa de los intereses públicos, como ocurre en el sistema español, con carácter general en materia penal y, en algunos supuestos específicos, de Derecho administrativo.

Mas sucede que no todos los intereses sociales o colectivos son seleccionados como intereses públicos. Razones de filosofía política y circunstancias de tiempo y lugar determinan la función que en este orden desempeña el Estado.

Superado el modelo histórico del Estado liberal, la consideración de la juridicidad de unos intereses sociales o colectivos distintos de los individuales y de los públicos (en cuanto no formalizados como tales, la formalización completa de los intereses sociales como públicos conduciría al Estado totalitario) llevó al legislador a regular determinadas materias con limitaciones y cortapisas al ámbito de la autonomía de la voluntad privada, procurando un equilibrio entre los valores libertad-igualdad. Surgieron así las legislaciones protectoras del trabajo, de la mujer, de los niños... La «cuestión social» por antonomasia en el siglo xIx fueron las relaciones de trabajo. Cuestión social y cuestión obrera se identificaron como sinónimos. Tal situación, en lo que al procesalismo concierne, provocó el nacimiento de jurisdicciones especiales de trabajo y el reconocimiento de un derecho autotutelar de primera magnitud, el derecho a la huelga, que en cierto sentido comporta reconocimiento también de la insuficiencia jurisdiccional como medio heterocompositivo garantizado por el Estado.

En las sociedades posindustriales de nuestro tiempo, los intereses sociales han desplazado sus objetivos de los derechos laborales o profesionales, que han encontrado su marco de acomodo y de tutela genuina en el desarrollo sindical y se han polarizado en torno al logro de mayores cotas de "calidad de vida», entendida esta expresión en sentido amplio. Interesa la calidad del consumo, la veracidad de la publicidad, la salubridad del medio ambiente, el acceso de todos a la cultura... En definitiva, la nueva problemática pone en evidencia las insuficiencias legislativas y de protección jurisdiccional en estas materias, descubre el desamparo jurídico en que se encuentran los intereses sociales y colectivos aglutinados en torno a estas preocupaciones subjetivas y carencias y limitaciones objetivas. La nueva problemática social coloca en primera línea de atención estos intereses sociales o colectivos, que suelen congregarse alrededor de sectores o grupos, a los que se llama difusos, mal regulados y dificultosamente protegidos. 


\section{DIFICULTADES DE LA NOCION «INTERESES DIFUSOS»}

Dado, pues, que el concepto de intereses difusos, tal como viene transmitido por la doctrina, se adscribe, como un Jano bifronte, de una parte; a lo que es aspiración o desideratum - problemas de iure condendo- y, de otra, a los logros modestos e insuficientes - cuestiones de iure condito-, de lo que se infiere la extrema labilidad de aquél, conviene que establezcamos algunas precisiones antes de continuar adelante.

De iure condendo los intereses difusos ofrecen una línea conceptual de naturaleza sociológica capaz de movilizar corrientes de opinión que procuran reformas legislativas tendentes a la regulación y desarrollo normativo de las materias enunciadas en el apartado anterior (consumo, ecología, urbanismo, cultura, vivienda, tercera edad, salud, etc.). Sin embargo, en este orden preconstitucional y prelegislativo los intereses difusos carecen de juridicidad.

De iure condito los intereses difusos pueden adoptar diferentes manifestaciones: 1) reconocimiento de algunos derechos o principios en los que se cristalizan o se enuncian estos intereses con rango constitucional, 2) desarrollo legislativo de estos principios o derechos, 3) tutela procesal ordinaria de los mismos y 4) tutela procesal específica adecuada a la naturaleza de los intereses difusos. Estos planos son cumulativos. La juridicidad en estos casos de los intereses difusos y su justicialidad están en función de las características de cada ordenamiento jurídico y del grado de desarrollo del mismo.

Supuesta, en este sentido, la juridicidad de estos intereses porque medie algún reconocimiento normativo $\mathrm{y}$, consecuentemente, algún modo de tutela judicial, habría que distinguir dentro del concepto de «intereses difusos» entre estos intereses formalizados en cuanto derechos (derecho a la cultura, derecho a la calidad del consumo, derecho al medio ambiente adecuado, etc.) y estos intereses en cuanto situaciones jurídicas de ventaja, utilidad o perjuicio de naturaleza grupal y nucleadas en torno a estos reconocimientos legislativos que merezcan tutela judicial. En sendos casos, si la tutela procesal se reconduce a los esquemas clásicos, esto es, legitimación de quien afirme la titularidad del propio derecho o legitimación de quien afirme un interés directo relativo a una situación jurídica individualizada propia del accionante, la problemática típica de los intereses difusos se habría perdido deglutida por la inercia del régimen clásico de legitimaciones.

Pero imaginemos que, establecida la distinción esbozada, se arbittan medios judiciales y procesales para que, además del interesado directamente por la situación individual o del titular presunto del derecho, otras personas u órganos puedan gestionar procesalmente el derecho o interés ajeno en cuanto propios también por solidarios: en tal caso nos encontramos de lleno con la temática general y fin primordial que persigue la doctrina sobre los intereses difusos.

\section{APROXIMACION AL CONCEPTO DE «INTERESES DIFUSOS»}

De esta guisa podemos acercarnos con pretensiones de mayor aproximación al concepto de intereses difusos. 
La existencia de estos intereses se hace notar en las modernas sociedades industriales como consecuencia de la creciente aspiración a mejorar la calidad de la vida en todas sus vertientes, deteriorada en muchos sentidos y amenazada por la propia civilización industrial, todavía poco evolucionada para responder a las exigencias comunitarias.

La respuesta a esas demandas se formula en sede constitucional mediante el reconocimiento de determinados derechos o principios generadores de intereses jurídicos (derecho a la protección de la salud, derecho a la educación, protección a la familia, protección a la madre soltera, etc.).

Legislativamente, estos derechos y principios se traducen en desarrollos desiguales, pero en general con la común pretensión de trascender al sujeto individual como titular del derecho o interés.

Traduce esta nueva legislación social una «toma de conciencia» sobre exigencias colectivas que implican mayores grados de cohesión social y de interdependencia solidaria. Lo típico de estos intereses sociales o colectivos que se denominan difusos es su acotación por grupos o clases o sectores de manera más o menos extensa, según los casos. Por razón de esta distribución de los intereses sociales representativos de clases, grupos o colectivos más o menos extensos, surgen conflictos a veces entre la satisfacción de los intereses de un grupo respecto de los de otros, lo que lleva a poner de relieve otra nota que acompaña al concepto de intereses difusos: la conflictualidad.

En efecto, estos intereses se mueven en la línea de reconocimiento de los derechos humanos llamados económicos, sociales y culturales, diferenciados de los derechos cívicos y políticos. Estos últimos, en cuanto libertades o derechos formales, se concretan con mayor facilidad y su satisfacción, por tanto, ofrece menos dificultades. En cambio, en cuanto a los primeros, se hace muy difícil precisar el alcance jurídico de su contenido y lo que pudieran denominarse directivas para su expansión y plena satisfacción. Concurren en este último sentido las discrepancias políticas en torno a la construcción del modelo de sociedad que permita la mejor o más indicada satisfacción de éstos. Pero estas dificultades no deben excluir bases de común asentimiento y concordia que permitan establecer los contenidos mínimos concretos de los citados derechos.

El término «difuso» alude, pues, entre otras posibles acepciones (difundido, propagado), a la escasa precisión jurídica de los mismos, a su inconcreción.

Esta imprecisión o difusión de los intereses sociales o colectivos mencionados se manifiesta acusadamente en tres planos: subjetivo, objetivo y formal.

Subjetivamente porque estos intereses se refieren a colectivos poco precisos en su composición, generalmente anónimos e indeterminados, aunque, con dificultades, determinables. Subjetivamente también porque, en la medida en que estos intereses se densifican en derechos constitucionalmente reconocidos, la titularidad de estos derechos, que, aunque individuales, tienen su proyección y desarrollo en el grupo social, motivan disquisiciones de filosofía jurídica todavía no cerradas entre el individualismo social y el socialismo. En suma, abren paso a la polémica sobre si puede hablarse de unos derechos de las formaciones sociales como categorías diferenciadas en cuanto a la titularidad de los derechos de la persona. Subyacen en este planteamiento filosofías dispares que van desde el corporativismo al socialismo estatista, pasando por la doctrina social de la Iglesia sobre los «cuerpos intermedios»: thay entidades «na- 
turales» capaces de derecho distintas de la persona humana? $\mathrm{O}$ en todo caso: ¿no es cierto que los derechos de las personas jurídicas, que son creaciones humanas, aunque respondan a unas necesidades naturales, tienen un valor secundario y subordinado a aquellos otros?

Sin pretender resolver el problema en este trabajo, no cabe duda que esta indeterminación patente en la doctrina sobre los derechos de formación social influye en la ambigüedad de la titularidad.

Objetivamente, estos intereses son también difusos o imprecisos, porque el alcance de las prestaciones debidas y la determinación del sujeto que tiene a su cargo la liberación del deber correspondiente para la satisfacción del interés no están determinados. Se refieren a derechos en los que el contenido del objeto se difumina, ora sea porque los mínimos no están fijados legislativamente, ora sea porque los obligados son múltiples y cada uno tiene algo que poner para el cumplimiento o realización del derecho.

Formalmente, la ambigüedad subjetiva y objetiva de los derechos que nuclean a su alrededor, los «intereses difusos», influye en una «accionabilidad» o justicialidad también difusa o imprecisa, porque el problema de la titularidad abre a la consideración de la doctrina el estudio de nuevas formas de acceso a la justicia en grupo y porque, con independencia ya de la titularidad del derecho, al ser un grupo el afectado en una determinada materia, pueden arbitrarse nuevas formas de intervención procesal o de representación de los intereses afectados por la parte actuante que desbordan los esquemas clásicos del Derecho procesal.

\section{LA TUTELA PROCESAL DE LOS «INTERESES DIFUSOS»}

Procesalmente, pues, las novedades que aporta la doctrina de los «intereses difusos» es la de propugnar una transformación en el acceso a la justicia. Cambio operado en determinados ordenamientos, reconocido en resoluciones jurisprudenciales avanzadas e innecesario en los países de Derecho consuetudinario que permiten formas de accionar, a cuyo amparo cabe el cobijo de los intereses de un grupo sin necesidad de que todos los que forman parte del mismo accionen.

En efecto, limitada la legitimación a quien actúe afirmando un derecho o interés propio, muchas veces la pequeñez de lo que individualmente puede reclamarse, el temor al enfrentamiento con fuerzas más poderosas que debilitan la posición de parte, frustran el fin de reintegración del ordenamiento jurídico perturbado, que cumple también la iniciativa privada, al no ejercitarse el derecho a la jurisdicción.

Cuando a la parte no sólo se le atribuye calidad para actuar en nombre propio, sino en el de todos los posibles afectados, la importancia de ésta crece y su acción trasciende del propio interés para proyectarse en el interés de todo el grupo que asume.

Pero además, si se piensa que los intereses que estos derechos congregan suelen o pueden motivar agrupaciones con personalidad jurídica (sociedades, asociaciones o fundaciones) encargadas de velar por los mismos, cabe también que el ordenamiento jurídico legitime a estas entidades para que actúen pro- 
cesalmente en defensa de estos intereses, no sólo en cuanto se refieren a los asociados, socios o patronos, sino en cuanto se proyectan en la generalidad de todos los que sean partícipes del interés colectivo en cuestión.

Estas modalidades de legitimación, que rompen sin duda los moldes clásicos, obligan a regulaciones procesales que garanticen la evitación de fraudes o extorsiones basados en el poder legal que confieren, excedido de la propia personalidad. Se establecen así filtros, normalmente judiciales, que de alguna manera aseguran prima facie la seriedad y buen propósito de las reclamaciones formuladas, así como la consistencia y representatividad de la entidad o persona actuante. De aquí que algunas legislaciones consideren que no todas las entidades pueden utilizar estas facultades legitimatorias extraordinarias, sino sólo aquellas que tienen una representatividad cualificada.

En otro orden, la doctrina sobre los intereses difusos debe conducir en el plano procesal, sobre todo en aquellos ordenamientos que, como el español, no tienen regulada esta materia en lo relativo al proceso civil, a una amplitud respecto al concepto de interés como base para propiciar la intervención adhesiva en el proceso civil de todos cuantos se pudieran ver afectados por la sentencia.

En suma, las inferencias de esta temática sobre el proceso civil obligan a revisar conceptos tradicionales: el derecho a la jurisdicción debe abrirse a legitimaciones grupales que permitan un modo complementario de acceso a la justicia; la válida constitución de la relación jurídica procesal obligará en muchas ocasiones a un llamamiento a terceros interesados; la distribución de la carga de la prueba se verá afectada en determinadas reclamaciones por la flexibilidad de su aplicación; la eficacia de la cosa juzgada habrá de hacerse extensiva a terceros no intervinientes; la ejecución de sentencia deberá transformarse para dar acogida a condenas abiertas en cuanto a la cantidad en que consista la indemnización (dentro de unos límites, por supuesto) para permitir la comparecencia de anónimos perjudicados...

Estas novedades que en el campo de lo procesal aporta la doctrina sobre los intereses difusos no empece a que las formas tradicionales de tutela que atribuyen la representación de los intereses públicos o sociales al Ministerio Fiscal o a órganos más recientes, como el Ombusdman, pervivan y coexistan con aquéllas, pues sólo con una eficaz combinación de medios tutelares y de cobertura jurídica (constitucional, penal, administrativa y civil) cabe que se llegue a la adecuada protección de los intereses difusos.

\section{B) PERSPECTIVA CONSTITUCIONAL $Y$ PROTECCION PROCESAL} DE LOS INTERESES DIFUSOS EN ESPAÑA

\section{CONSTITUCION ESPAÑOLA E «INTERESES DIFUSOS»}

En España, la Constitución actual contiene normas que amparan las preocupaciones sociales inherentes a nuestro tiempo y otras que en concreto protegen los intereses sociales de grupo en un intento de equilibrar los valores 
libertad e igualdad, binomio sobre el que se asienta la dignidad de la persona humana y que es en el orden práctico del Derecho sana tensión dialéctica inspiradora del progreso social. En el núcleo de esta tensión está la problemática de los «intereses difusos» y en especial de la efectividad de su tutela, tanto legislativa como judicial.

Dice, en efecto, el artículo 9.2 de la Constitución que corresponde a los poderes públicos promover las condiciones para que la libertad y la igualdad del individuo y de los grupos en que se integra sean reales y efectivas, remover los obstáculos que impidan o dificulten su plenitud y facilitar la participación de todos los ciudadanos en la vida política, económica, cultural y social.

Al margen (por no ser ésta la ocasión) de la polémica de filosofía políticosocial que subyace tras el enunciado constitucional, no cabe duda que en la expresión «libertad e igualdad de los grupos» es donde se sitúa el fundamento constitucional de protección a los intereses difusos, pues éstos son, en definitiva, intereses sociales o colectivos de un grupo, clase o comunidad más o menos extensa nucleados en torno a la ansiada efectividad de un derecho fundamental (reconocido o no constitucionalmente), generalmente de los llamados económicos, sociales o culturales, aunque puedan también incluirse en este concepto algunas de las libertades clásicas (por ejemplo, libertad de expresión) en cuanto ofrecen un interés social difuso de cuya satisfacción efectiva depende la realidad de aquélla.

La Constitución reconoce los derechos que originan, en cuanto jurídicos, los intereses difusos. Así, el derecho a la protección de la salud (art. 43), el acceso a la cultura a la que todos tienen derecho (art. 44), el derecho a disfrutar de un medio ambiente adecuado (art. 45), el derecho a disfrutar de una vivienda digna y adecuada (art. 47). También la Constitución, sin catalogarlos como derechos, establece «principios rectores de la política social y económica» generadores de intereses de esta naturaleza: protección social, económica y jurídica de la familia; protección integral de los hijos, iguales éstos ante la ley, con independencia de su filiación; protección de las madres; protección de los niños (art. 39); régimen público de seguridad social que garantice la asistencia y prestaciones sociales suficientes ante situaciones de necesidad (art. 41); protección del patrimonio histórico, cultural y artístico (art. 46); protección de los disminuidos físicos, sensoriales y psíquicos (art. 49); suficiencia económica de las pensiones a los ciudadanos durante la tercera edad (art. 50). Mención aparte merece en este orden, por su trascendencia, la referencia a los consumidores: los poderes públicos garantizan la defensa de los consumidores y usuarios, protegiendo mediante procedimientos eficaces la seguridad, la salud y los legítimos intereses económicos de los mismos (art. 51).

Otros derechos y libertades, aunque tengan en algunos aspectos un contenido más concreto, ofrecen en otros zonas de intereses difusos. Así ocurre con el derecho a la educación, que ha de satisfacerse en régimen de libertad de enseñanza (art. 27), el derecho al trabajo (art. 35) y la libertad de empresa (art. 38). También las libertades públicas reconocidas a la persona en cuanto no sean eficaces o reales para personas físicas o jurídicas, dentro éstas de sus fines, promueven ondas de intereses difusos alrededor de grupos o sectores que deben merecer la atención legislativa y judicial. 
VI. SOBRE LA TUTELA PROCESAL, EN GENERAL, DE LOS «INTERESES DIFUSOS» EN EL SISTEMA ESPAÑOL

Una ojeada general sobre la tutela procesal de estos intereses en España conduce a una primera afirmación: en nuestra legislación procesal no se contemplan supuestos de legitimación amplia, grupal, que atribuyan a una persona física o jurídica representación para actuar en nombre e interés de todos los afectados, aunque éstos no litiguen. Excepcionalmente, dentro del ámbito del Estatuto de los Trabajadores se reconoce a la representación de los mismos en la empresa legitimación para emprender determinadas acciones con efectos que superan la relación interpartes.

Constitucionalmente no existe óbice para que en el futuro puedan construirse legalmente legitimaciones de esta naturaleza. El artículo 25 de la Constitución permite, en una interpretación concorde con el artículo 9.2, establecer una efectividad del derecho a la jurisdicción que incluya en el concepto «sus derechos e intereses legítimos» la tutela de estos intereses solidarios que son los intereses difusos. Lo mismo puede decirse de la regulación de la intervención procesal no contemplada en la actual Ley de Enjuiciamiento Civil.

Por supuesto que tanto el Ministerio Fiscal como el equivalente español del Ombusdman, o sea, el Defensor del Pueblo, están legitimados institucionalmente, el primero en la órbita de la legalidad, es decir, ante la jurisdicción ordinaria, y ambos en la órbita de la constitucionalidad para interponer el recurso de amparo, y el segundo además el de inconstitucionalidad, remedios que permiten tutelar también los intereses difusos.

Finalmente, al ciudadano se le atribuye también en ocasiones «acción popular», en línea con una tradición española que se manifiesta especialmente en el proceso penal y en determinados supuestos de interés público, superpuesto al interés social y difuso subyacente. Indudablemente, la acción popular en estos casos es un medio igualmente tutelar de los intereses difusos.

La Constitución, en este sentido, se muestra propicia a ampliar el campo de la acción popular. Así, el artículo 125 señala que los ciudadanos podrán ejercer la acción popular...

Examinaremos en los apartados siguientes cada uno de estos posibles accesos a la justicia en concreto.

\section{La acción colectiva de los comités de empresa}

Una de las innovaciones más importantes en materia laboral la constituye el régimen de legitimación atribuido al comité de empresa por el artículo 65 del Estatuto de los Trabajadores (Ley 8/1980, de 10 de marzo). Se reconoce - dice el precepto- al comité de empresa capacidad, como órgano colegiado, para ejercer acciones administrativas o judiciales en todo lo relativo al ámbito de sus competencias por decisión mayoritaria de sus miembros.

Si se tiene en cuenta que el comité de empresa es un órgano representativo del conjunto de los trabajadores en la empresa, se llega a la conclusión de que se ha introducido un tipo de legitimación colectiva que no tiene parangón 
en nuestro Derecho (por influencia sin duda del Derecho italiano), llamada en su desarrollo y práctica ulterior a remover la concepción tradicional del Derecho del trabajo en cuanto que algunas de las competencias asignadas por ley al referido órgano sindical tienen carácter amplio.

\section{Legitimación del Ministerio Fiscal en cuestiones de interés social}

El Ministerio Fiscal, según la Constitución, tiene entre otras misiones (art. 124) la de procurar ante los tribunales la satisfacción del interés social. Esta misión se incardina en un marco más amplio, que sitúa en primer término la promoción de la acción de la justicia en defensa del interés público.

Aunque interés social e interés público puedan superponerse, a nuestro entender son conceptos distintos. El reciente estatuto orgánico del Ministerio Fiscal, aprobado por Ley 50/1981, de 30 de diciembre, repite en su artículo 2 el precepto constitucional. Y al tratar de las funciones establece que corresponde al mismo tomar parte en defensa de la legalidad y del interés público o social en los procesos relativos al estado civil y en los demás que establezca la ley, con lo que parece identificar interés público e interés social, con anfibología, sin embargo, puesto que la conjunción empleada permite dar a la frase un sentido disyuntivo o copulativo.

Corresponde, en definitiva, a las leyes determinar los supuestos de legitimación del Ministerio Fiscal para la satisfacción del interés social, en cuya expresión pueden incluirse sin dificultad los «intereses difusos».

Pero las leyes vigentes no se muestran generosas en esta materia. Por tanto, la cláusula remisora a las leyes, que puede tener un alcance «pro futuro», carece en la actualidad de relevancia.

Se sigue de la constatación de esta realidad la confirmación, por lo menos hasta el momento, del criterio que apunté en otra oportunidad acerca de las funciones del Ministerio Fiscal en esta materia, opinión avalada también por la doctrina y la práctica de otros países. A saber: la preparación específica del Ministerio Fiscal de estos funcionarios habituados a colaborar con el juez en la investigación del delito en la fase de instrucción sumarial y a mantener la acusación pública ante los tribunales de lo penal les hace, quizá por la misma realidad de su diaria e intensa ocupación profesional, menos propicios a la representación de intereses civiles vinculados a complejos fenómenos económicos o sociales.

De otra parte, los «intereses difusos» no son a veces intereses generales, sino intereses de clase o de grupos sociales determinados que originan conflictualidad ideológica, lo que puede en ocasiones hacer peligrar la neutralidad social del Ministerio Fiscal.

En consecuencia, no debe esperarse que sea la legitimación al Ministerio Fiscal en estas cuestiones el modo único, ni siquiera principal en relación con otros, de resolver los problemas que plantea la litigiosidad de los «intereses difusos».

En otro orden, se reconoce al Ministerio Fiscal legitimación para interponer el recurso de amparo constitucional en los casos y formas previstos en la 
Ley Orgánica del Tribunal Constitucional, junto con otras funciones ante esta jurisdicción. Como quiera que estas funciones, en lo que a la interposición del amparo se refiere, son iguales a las del Defensor del Pueblo, deben aplicarse a éstas las consideraciones que haremos a propósito de esta institución, bien entendido que, por las razones ya esbozadas, en la práctica la función de interposición del recurso de amparo por el Ministerio Fiscal estará condicionada por los factores que se apuntaron.

\section{3. «Acción popular» en materia de «intereses difusos»}

Los ciudadanos, por razón de su ciudadanía, están también llamados en ocasiones al desempeño de una tarea activa en la promoción de la justicia. Así ocurre en particular, desde el punto de vista de la iniciativa procesal, cuando se atribuye a los mismos «acción popular», es decir, cuando se confiere una legitimación abierta para que cualquier persona tenga poder para solicitar la protección procesal en una determinada situación jurídica.

Dentro del tema acotado bajo la rúbrica de los intereses difusos, el ordenamiento español ofrece los siguientes ejemplos:

1) En materia urbanística. El urbanismo exige la intervención administrativa y la producción de actos aprobatorios, denegatorios de planes de ordenación urbana y ejecución de obras ajustadas a las normas generales especiales que delimitan el ejercicio de la actividad urbanística con sujeción a la legalidad. $\mathrm{La}$ Ley del Suelo reconoce a todas las personas físicas o jurídicas «acción» (legitimación) para exigir a los órganos administrativos competentes y a la jurisdicción en su manifestación contencioso-administrativa el cumplimiento de la legislación en materia de urbanismo. Regula esta legitimación en concreto el artículo 235.1 del TRLS de 9 de abril de 1976, que dispone que «será pública la acción para exigir ante los órganos administrativos y los tribunales contencioso-administrativos la observancia de la legislación urbanística y de los planes, programas, proyectos, normas y ordenanzas».

2) En materia de medio ambiente. El artículo 16 del Decreto 833/1975, de 6 de febrero, que desarrolla la Ley 38/1972 de Protección del Medio Ambiente Atmosférico, establece que cualquier persona natural o jurídica, pública o privada, podrá dirigirse por escrito motivado al alcalde, gobernador civil o director general de Sanidad expresando razonablemente la situación de contaminación y solicitando la tramitación del expediente para la declaración, si procede, de zona atmosférica contaminada.

Esta legitimación preprocesal, en cuanto convierte en interesado en el expediente a quien denuncia, procura una apertura legitimatoria en su caso ante la jurisdicción contencioso-administrativa. 


\section{C) JUSTICIALIDAD CONSTITUCIONAL DE LOS INTERESES DIFUSOS}

\section{CONSIDERACION GENERAL}

La justicialidad constitucional de los «intereses difusos» debe considerarse en razón de la justicialidad que corresponda a aquellos derechos de carácter económico-social o cultural en torno a los cuales decíamos que se generaban estos intereses en cuanto jurídicos.

Tal circunstancia ha de llevar a ponderar la efectividad de las garantías que a estos derechos asigna el artículo 53 de la Constitución, en especial el párrafo tercero, puesto que la mayoría de aquellos citados derechos se incluyen dentro del capítulo tercero del título I de la Constitución ( «De los derechos y libertades fundamentales»), que se refiere a los «principios rectores de la política social y económica».

Los derechos subjetivos públicos enunciados en este capítulo son de aquellos que un sector doctrinal denomina derechos subjetivos mediatos por contraposición a los. inmediatos, es decir, derechos condicionados en cuanto a la concreción de su prestación a futuros desarrollos legislativos, lo que prácticamente equivale a expresar que su naturaleza como derechos efectivos es sumamente precaria.

Ocurre, en efecto, con estos derechos que su regulación y contenido concreto está en función muchas veces del modelo que se adopte; no es lo mismo la influencia de una opción política en la que predomine el libre juego de las fuerzas sociales y económicas que una sociedad organizada según una planificación económica que prácticamente suponga un modelo dirigista... La satisfacción de muchos de estos derechos (ya he advertido que algunos de éstos figuran en el capítulo primero, y se dice ahora que otros de los que en éste se inscriben no tienen igual naturaleza) y el sesgo concreto de los principios que entmarcan el quehacer de los poderes públicos está sin duda muy condicionado por la acción política que se desarrolle. Y, sin embargo, el ideal sería que al menos determinados mínimos del contenido de esos derechos pudieran concretarse. Creo que es en este punto donde, con independencia de la acción legislativa que ha de estar informada por estos principios, la tarea del Tribunal Constitucional, a fuer de delicada, es, no obstante, en extremo indispensable.

La indeterminación de los conceptos no significa, como establece ya la doctrina de los conceptos indeterminados en materia contencioso-administrativa, que pueda producirse una arbitrariedad legislativa. Por el contrario, las normas jurídicas han de manifestar un desarrollo de la Constitución.

Así, pues, la primera defensa de estos derechos generadores de intereses difusos es la que resulta del ejercicio del recurso de inconstitucionalidad o de la cuestión de inconstitucionalidad.

Mas también el remedio del amparo constitucional podrá en ocasiones subvenir de modo directo e incluso indirecto a la tutela de estos intereses. 


\section{FUNCION DEL DEFENSOR DEL PUEBLO COMO TUTOR DE «INTERESES DIFUSOS»}

Al Defensor del Pueblo instituido por la Constitución (art. 54), regulado por Ley Orgánica 3/1981, de 6 de abril, le atribuye la norma fundamental funciones de gran trascendencia como promotor de la justicia constitucional, puesto que está legitimado para interponer el recurso de inconstitucionalidad (junto con los que tienen también este poder, aunque la legitimación sea más política: presidente del Gobierno, cincuenta diputados, cincuenta senadores, órganos colegiados de las Comunidades Autónomas y asambleas de las mismas) y para interponer el recurso de amparo (legitimación que comparte con el Ministerio Fiscal o con toda persona natural o jurídica que invoque un interés legítimo).

Desde esta doble vertiente, el Defensor del Pueblo puede convertirse, según el talante que inspire su actuación, en un verdadero protector de los «intereses difusos», con independencia de la atención que preste a las quejas por intereses concretos que en muchas ocasiones también darán pie para descubrir zonas de intereses difusos. Estas atribuciones, como es lógico, han de desarrollarse en los límites de la litigiosidad constitucional.

Como promotor del recuro de inconstitucionalidad, incumbe al Defensor del Pueblo velar para que las leyes que se promulguen no contengan disposiciones inconstitucionales que atenten a los derechos y principios reconocidos constitucionalmente, generadores de intereses difusos legítimos. No debe olvidarse que la mayoría de estos derechos y principios no gozan de la tutela privilegiada del amparo constitucional o recurso por violación anticonstitucional de derechos humanos (art. 53 de la Constitución). De aquí que la tutela de los intereses difusos que estos derechos cubren exija una cuidadosa revisión de las normas legales que se dicten para juzgar sobre la observancia o inobservancia de los preceptos constitucionales atinentes.

En especial como promotor del recurso de amparo, las posibilidades que tiene para tutelar los intereses difusos son aún mayores. Los derechos de referencia quedan excluidos directamente del recurso de amparo, pero los intereses difusos creados en su entorno son amparables con un empleo prudente e inteligente del artículo 14 de la Constitución, que establece el principio de igualdad ante la ley. Tal como está formulado permite apoyar interpretaciones más allá de la pura y mecánica igualdad formal ante la ley, puesto que sus contenidos concretos dan pie a una razonable y progresiva consideración del principio de igualdad real ante la ley. Una jurisprudencia atinada podrá desenvolver una doctrina que rompa con la distinción entre libertades formales y libertades reales.

De otra parte, algunos derechos de los citados como generadores de intereses difusos gozan directamente de amparo, como ocurre con el derecho a la educación y con la libertad de expresión.

Finalmente, es necesario señalar que, a diferencia de lo que acontece en el proceso civil, la LOTC regula con carácter general (art. 81) la coadyuvancia, es decir, la intervención adhesiva, que posibilita en procesos constitucionales la participación activa de los terceros interesados. Específicamente, además, establece la LOTC, con referencia a los recursos de amparo promovidos por 
el Defensor del Puebo o el Ministerio Fiscal (art. 46), la comunicación de la pendencia del proceso a los posibles agraviados conocidos y el anuncio del mismo en los diarios oficiales a efectos de comparecencia de otros posibles interesados.

\section{LA ACCION DE LOS CIUDADANOS} ANTE EL TRIBUNAL CONSTITUCIONAL

Los ciudadanos carecen de un derecho a la jurisdicción constitucional de carácter general. No se establece en su favor una cláusula abstracta de justicialidad, como ocurre con respecto a la jurisdicción ordinaria en el artículo 24 de la Constitución.

Sí gozan de un derecho a la jurisdicción constitucional limitado en materia de violación de determinados derechos fundamentales que pueden ser amparados por el Tribunal Constitucional. Y también de un derecho de petición ante la jurisdicción ordinaria para que introduzca, si lo considera pertinente, ante el Tribunal Constitucional la cuestión de inconstitucionalidad.

La legitimación que en este orden establece la Constitución está concebida en términos amplios. Se extiende a toda persona, natural o jurídica, que invoque un interés legítimo, y si bien la LOTC ha cambiado el lenguaje y se refiere a la persona directamente afectada o a quienes hayan sido parte en el proceso judicial correspondiente cuando el acto lesivo sea causado por órganos judiciales (art. 46), las interpretaciones que a estas expresiones se den no pueden ser restrictivas del texto constitucional.

$O$ sea, que sus posibilidades de acceder a la justicia constitucional para pedir la tutela de intereses difusos ha de construirse según los distintos de legitimación y medios procesales que les brinda la Constitución y la LOTC.

Estas posibilidades son nulas con el recurso de inconstitucionalidad. Son casi nulas con la cuestión de inconstitucionalidad, puesto que la actuación se limita a pedir al órgano judicial en el proceso concreto que promueva la consulta sobre la inconstitucionalidad de un precepto legal aplicable ante el Tribunal Constitucional. En cambio, estas posibilidades jurídicas son amplias en materia de amparo.

Ningún problema, en efecto, surge respecto de los derechos directamente amparables, esto es, las libertades y derechos reconocidos en el artículo 14 de la Constitución y en la sección primera del capítulo segundo del títuló $I$, más el derecho a la objeción de conciencia reconocido en el artículo 30.

Pero sucede que, con independencia de los intereses difusos presentes en torno o alrededor de las libertades formales clásicas, y especialmente en cuanto a determinados derechos (derecho a la educación, derecho de antena derivado del derecho a comunicar o recibir libremente información, etc.), son los derechos económicos sociales y culturales los que, por su mayor indefinición y más incompletos, provocan una más extensa y anónima insatisfacción, originadora, sin embargo, de expectativas que se nuclean en torno a grupos o sectores portadores de intereses difusos.

Estos derechos incompletos, junto a orientaciones y limitaciones de los poderes públicos, están regulados en el capítulo tercero del citado título. Y el 
párrafo tercero del artículo 53 de la Constitución, tras señalar que el respeto y la protección de los principios reconocidos informarán la legislación positiva, la práctica judicial y la actuación de los poderes públicos, añade que sólo podrán ser alegados ante la jurisdicción ordinaria de acuerdo con lo que dispongan las leyes que los desarrollen. Según este precepto constitucional, los mencionados principios son directrices de las que no puede prescindir el legislador; también la jurisprudencia debe inspirarse interpretativamente en los mismos; el último inciso viene a decir que no pueden fundarse pretensiones de las leyes que los desarrollen. La alegación, por tanto, de estos principios o derechos incompletos ante los tribunales de la jurisdicción ordinaria tienen ese límite.

Lo que no está prohibido sensu contrario es la invocación de los mismos ante el Tribunal Constitucional. ¿De qué manera? Por supuesto, cuando las leyes que se dicten infrinjan estos principios o derechos, cuando desconozcan o perturben la vigencia de estos principios constitucionales. El remedio en este caso sería el recurso de inconstitucionalidad promovido por alguno o algunos de los restringidos miembros del «club» de legitimados o por medio de una cuestión de inconstitucionalidad.

¿No cabe, pues, el amparo? Evidentemente, no. No hay amparo directo o proceso propiamente de amparo por las violaciones que se cometan por los poderes públicos a desarrollar o no tener en cuenta estos principios. Mas puede, a mi entender, construirse - $\mathrm{y}$ es esto a lo que llamo amparo indirecto- pretensiones de amparo constitucional fundadas en algunos de los derechos directamente amparables relacionando la lesión constitucional con la infracción de alguno de estos derechos o principios, demostrando que esta vulneración repercute en la virtualidad del derecho invocado como amparable.

Lo explicaré de modo más detallado. Generalmente, los derechos y principios que componen este capítulo se refieren más al valor igualdad que al valor libertad. Los derechos económicos sociales y culturales pretenden la realización de la justicia social, es decir, de un ideal igualitario.

Los desarrollos legislativos que contienen discriminaciones veladas, tepartos injustos o simplemente que no contemplan o hurtan los problemas que plantean la observancia de aquellos principios o derechos vulneran el principio de igualdad ante la ley reconocido en el artículo 14. Y el artículo 14 sí que es directamente amparable. Cuando la norma produzca el agravio a ese principio de igualdad porque no se respeten o sean vulnerados algunos de los derechos o principios reconocidos en el capítulo tercero, estaremos en presencia de un posible caso de amparo al que denomino indirecto por el modo en que el razonamiento sobre la infracción debe articularse.

Cierto que la doctrina constitucional no se ha lanzado a aventuras interpretativas, que, de otra parte, habían de ser criticadas negativamente.

Pero cierto también que corresponde a la doctrina abrir cauces de interpretación racional que impidan el estancamiento en rigideces formales poco aptas para valorar en todas sus dimensiones la plenitud de la coherencia constitucional.

La amplitud, en consecuencia, del tema decisorio en los recursos de amparo depende de las vitualidades con que se conciba el principio de igualdad reconocido constitucionalmente.

Mas también, subjetivamente, una interpretación no generosa, sino simple- 
mente ajustada a la Constitución, permite no sólo que las personas jurídicas actúen en defensa de los derechos tutelados, sino que se pida la tutela de intereses solidarios, de intereses difusos.

Las teorías, por tanto, del sujeto exponencial, es decir, de la parte actuante en razón de unos intereses colectivos de grupo o sctoriales, puede ser acogida constitucionalmente. Otra cosa es que la admisión de teorías de esta naturaleza deba rodearse de las máximas garantías para impedir colectivizaciones soterráneas enemigas de la personalidad y de su desarrollo dentro de las formaciones sociales.

\section{NOTA BIBLIOGRAFICA}

La tutela degli interessi difussi nel Diritto Comparato (con particolare riguardo alla protezione dell'ambiente e dei consumatori), Congreso de Palermo, 22-25 marzo 1975, Giuffrè, Milán, 1976; La azioni a tutela di interessi collettivi, Congreso de París, 11-12 junio 1974, Cedam, Padua, 1976; José Almagto Nosete, Nuevos borizontes del derecho a la justicia, Madrid, 1977; Ada Pellegrini Grinover, «A tutela jurisdiccional dos intereses difusos», en Revista Uruguaya de Derecbo Procesal, núms. 3-4, 1977, págs. 11 y sigs.; Gutiérrez-Alvis y Armario, «La defensa de los intereses públicos difusos», en Estudios jurídicos, Sevilla, 1978, págs. 664-667; José Carlos Barbosa Moreira, $A$ ação popular do direito brasileiro como instrumento de tutela jurisdiccional dos chamados interesses difusos, estudio en honor de Enrico Tulio Liebman, vol. IV, Giuffrè, Milán, 1979, págs. 73 y sigs.; Vigoriti, Interessi collettivi e processo, Giuffrè, Milán, 1979; Sánchez Morón, «La participación del ciudadano en la Administración pública», en Intereses difusos, Madrid, 1980 , págs. 111-134. 